\title{
Analysis on Research and Application of China C2C Websites Evaluating Index System
}

\author{
Rongying Zhao ${ }^{1}$ and Ruixian Yang ${ }^{2}$ \\ 1 Associate professor of School of Information Management, Wuhan \\ University, \\ Vice director of Research Center for Chinese Science Evaluation of \\ Wuhan University, Wuhan, 430072, China \\ Research Field:Knowledge Network and and Knowledge Management, \\ Informatrics and Scientific Evaluation, E-mail:zhaory999@yahoo.com.cn \\ 2 A postgraduate student of School of Information Management, \\ Wuhan University, Wuhan 430072 , China \\ Research Field: Information Management and Knowledge \\ Management,E-mail:dylis85@126.com
}

\begin{abstract}
Recently in China, the speed of the development of the $\mathrm{C} 2 \mathrm{C}$ websites has been very swift. This article is on the research actuality and the problems of the China $\mathrm{C} 2 \mathrm{C}$ websites, and studies the index system of China $\mathrm{C} 2 \mathrm{C}$ 's website evaluation. Conclusions and suggestions are given by using the index system and taking Taobao, eBay and paipai websites as example to analyze.
\end{abstract}

\section{Introduction}

Electronic Commerce, E-commerce for short, in the opening network environment of Internet, based on the application way of Browser/Client, is a new commercial operation mode, implementing customers' shopping from network, network business trade and online electronic payment. At present in China, according to the trading object, the mode of the E-commerce is divided into five categories: business organization to business organization $(\mathrm{B} 2 \mathrm{~B})$, business organization to customers $(\mathrm{B} 2 \mathrm{C})$, business organization to government administration department (B2G), customers to government administration department (C2G)and customers to customers $(\mathrm{C} 2 \mathrm{C}) . \mathrm{B} 2 \mathrm{G}$ and $\mathrm{C} 2 \mathrm{G}$ is $\mathrm{E}$-commerce behavior of government, not aiming to profit, involving government stock, applying to customs and declaring dutiable goods online, ect, have little effect on the E-commerce industry. Compared to $\mathrm{C} 2 \mathrm{C}$,

Please use the following format when citing this chapter:

7hao, R., Yang, R., 2007, in IFJP International Federation for Information Processing, Volume 251, Integration and Innovation Orient to li-Society Volumel, Wang, W. (lids), (Boston: Springer), pp. 431-442. 
B2C must be the best E-commerce mode in terms of the profit in China. Although having appeared later, $\mathrm{B} 2 \mathrm{C}$ and $\mathrm{C} 2 \mathrm{C}$ develop faster.

Recently new data from "China C2C online shopping in 2006" survey was released by China Internet Network Information Center (CNNIC) and iResearch2006. The short report of China online shopping shows that the volume of trade of China $\mathrm{C} 2 \mathrm{C}$ websites is far greater than that of $\mathrm{B} 2 \mathrm{C}$ in 2005 , and the period from 2005 to 2010 will be a period when China C2C market has a huge development. In this period, a great deal of capital and person with ability, will swarm into $\mathrm{C} 2 \mathrm{C}$ market, and the extent of participating the online trade will be gradually deepened [5] [2]. Facing to the flourishing development tendency of China $\mathrm{C} 2 \mathrm{C}$ market, a lot of customers will pay more attention to many questions such as transportation, payment, credit, the security of the network and so on. Faced with these Gordian knots, how to deal properly will have a function in the development of China $\mathrm{C} 2 \mathrm{C}$ itself, and the trade of business. In this article, according to those questions above, research and discussion on China $\mathrm{C} 2 \mathrm{C}$ websites evaluating index system are given. Through this study, it is expected that index system can evaluate the China $\mathrm{C} 2 \mathrm{C}$ website scientifically and reasonably, with the aim to accelerate China $\mathrm{C} 2 \mathrm{C}$ website's development healthily and swiftly.

\section{Actuality and Problems of China C2C Evaluation}

\subsection{Actuality}

So far in China many organizations and scholars have attributed to the evaluation of the E-commerce websites, especially $\mathrm{B} 2 \mathrm{~B}, \mathrm{~B} 2 \mathrm{C}$ and $\mathrm{B} 2 \mathrm{G}$, but seldom on $\mathrm{C} 2 \mathrm{C}$. The research from CNNIC, iResearch, and scholars is on the subject of survey and collection of data, but not on the evaluation and application of index system. In order to adapt to the speed of the China $\mathrm{C} 2 \mathrm{C}$ development, adopting from $\mathrm{B} 2 \mathrm{~B}, \mathrm{~B} 2 \mathrm{C}$ and B2G websites' evaluating index system and considering C2C's self-identity, there will be research and discussion on China $\mathrm{C} 2 \mathrm{C}$ website based on evaluating an index system. Using data investigated by those authoritative organizations, for analyzing three websites are chosen for further analysis and key problems are immerged.

\subsection{Problems}

From the analysis of research actuality above, we can identify the following problems: firstly, the research on the China $\mathrm{C} 2 \mathrm{C}$ website evaluation is just on the stage of data investigation and collection, or data analysis, but not having integrated an evaluating index system; secondly, some evaluating indexes are not entire and comprehensive, nor forming a system and analysis of application. 


\section{Design of China C2C Website Evaluating Index System}

Through the research actuality and problem of China $\mathrm{C} 2 \mathrm{C}$ website evaluation, it is supposed that it is necessary to research deeply on China $\mathrm{C} 2 \mathrm{C}$ website evaluating index system and analyze China $\mathrm{C} 2 \mathrm{C}$ website using the index system, then concludes with the development actuality and problems of China $\mathrm{C} 2 \mathrm{C}$ websites, using scientific method and giving constructive critique according to the problems.

\subsection{Index of Evaluation}

\subsubsection{Network Impact}

Network impact is an important index to the evaluation of the website and mainly displayed in network linking. Network linking is an essential tool to organize the information from Internet and deliver its relationship. We take "Inlink" (Inbound Link) as the index of evaluating information resource from websites. Generally it concludes number of Inlink WebPages and number of Inlink Websites [10] [9].

(1) Number of Inlink Webpages.

The number of Inlink Webpages is to describe the web information resource that points to the object we research excluding its internal links. Generally the greater the number of Inlink Webpages, the higher the usage of this website and the greater the network impact of this website. But the short-coming of this index is that if the inlink of the object we research comes from small websites, even though the number of Inlink Webpages is great, we can not tell if the website impact is also great, so when using this index, we choose number of Inlink Websites to modify simultaneously.

(2) Number of Inlink Websites.

Number of Inlink Websites is how many other inlinks pointing to the website we research, which is also used to weigh the network impact directly, not just to modify the number of Inlink Webpages as the index of evaluating index system.

3.1.2 Website Fluidity Index

Website fluidity is the most direct reflection of how the website can be used. Generally there are four indexes: the number of visiting, the number of pages visited, the average pages visited and average load time to scale the website fluidity.

(1)Number of Visiting.

The number of visiting means that how many people visit the website in a certain time. There are two ways to evaluate this index: The first one is calculating simply the number of people who visited the website, that is, in a certain time, if one person visited the website more than one time, the times will be added up. The second one is neglecting the repeat visiting in a certain time, that is, we just record one time for a certain user no matter how many times he or she visited. Compared with the first way, the second way can compute the real number of people who browse and use the website in a certain time. In this article, it takes the number of an average of million visiting who installed the Alexa as the value of the index of the number of visiting.

(2)Number of Pages Visited. 
The total pages people visited in a certain time. This is the common evaluating index for all the websites, so it is also necessary here [12]. It takes the number of people installing Alexa per million as the value of this index. Because the ratio relationship between two indexes above is not directly accurate, that is to say, it may be not true that the greater the number of visiting equates with a greater the number of pages visited. One user reads one page carefully, but browses a lot of pages extensively. Thus it is more objective to take both of number of visiting and number of pages visited simultaneously as the indexes of website fluidity.

(3)Average Pages Visited.

Average pages visited means that the average number of webpages one person browses and acquires in a certain time. Webpages can either be static, or dynamic according to users' requirement. Average number of visiting and visiting time are all the indexes reflecting website's "mucosity" .However because of the different reading habit, the time users take may differ greatly even if they get the same amount of information. Moreover, many browsers will not log out spontaneously after visiting the website. At the same time, the system continues to calculate the visiting time. Obviously it is more reasonable to take average pages visited as an index to weigh "mucosity". Furthermore, through the number of visiting and the average pages visited, we can still obtain the total amount of information delivered by a website in a certain time.

(4)Average Load Time.

Average load time, an indirect index to scale website fluidity, means the time of the webpages loaded in a certain time. The more the average load time, the more the people who visited the website and the more the website fluidity. Whenever the number of the people exceeds a certain value, the burden of the server overtaking can also result in the longer load time, without taking account of technological problems here.

\subsubsection{Network Visibility}

The statistical report of China Internet Website Development Actuality in July, 2005 shows that $84.5 \%$ network users got to know new websites depending on search engine, and $58.2 \%$ retrieved information by search engine. Therefore we can see that search engine is critical to the fact that whether the information from internet can be used by network users. Accordingly one of the important ways to enhance the rate of website usage is to make as much information as possible acquired and indexed by search engine. It is the quantity of information from a certain website which can be acquired and indexed by search engine as network visibility. We commonly take the number of webpages as measure unites [7].

\subsubsection{Volume of Market Trade}

As another index, volume of market trade plays a big role of evaluating websites. It is also the direct manifest of the E-commerce market's outstanding achievement. Here we take the ratio of trading volume as the "second class" index.

Consequently, the eight indexes we take in this research are number of Inlink Webpages, number of Inlink Websites, number of visiting, number of pages visited, average pages visited, average load time, network visibility, ratio of volume of market trade. 


\subsection{Design of China C2C Website Evaluating Index System}

(1)Design with Analytic Hierarchy Process (AHP) Method

Analytic Hierarchy Process (AHP) is a useful decision-making method brought forward in 1970 by T.L.Satty, a famous operational researcher from America. This method is often successfully applied to system analysis and strategic research of economics, technology and politics. Its basic idea is to connect stable quantify with quality and process people's subjective opinion through the form of quantity. Scholars advanced a series of mark and degree methods in the process of using AHP. The earliest method is 1-9 mark and degree which is used extensively [8]. In this article, we use AHP to design China $\mathrm{C} 2 \mathrm{C}$ website evaluating index system and mark and degree methods to calculate weight of every index.

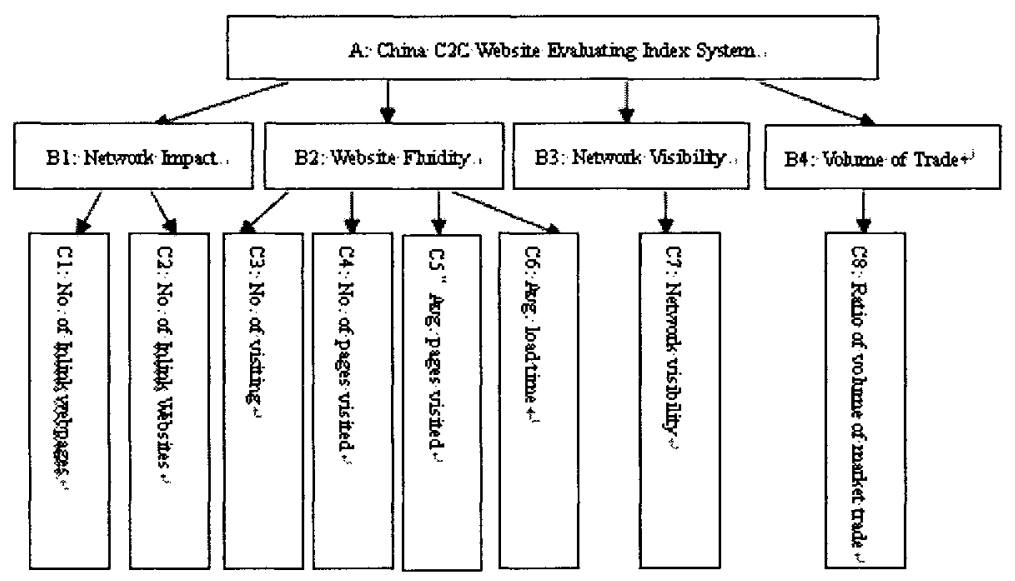

Fig.1. Design of China C2C Website Evaluating Index System

(2) Weight Calculation

Giving the value of the comparative result between two indexes at random by using AHP method [11]:

Table 1. Compare one index with the others at Random

\begin{tabular}{|l|l|l|l|l|}
\hline Index & $\begin{array}{l}\text { Website } \\
\text { Impact }\end{array}$ & $\begin{array}{l}\text { Website } \\
\text { Fluidity }\end{array}$ & $\begin{array}{l}\text { Network } \\
\text { Visibility }\end{array}$ & $\begin{array}{l}\text { Volume of } \\
\text { Trade }\end{array}$ \\
\hline $\begin{array}{l}\text { Website } \\
\text { Impact }\end{array}$ & 1 & $1 / 2$ & 1 & $1 / 2$ \\
\hline $\begin{array}{l}\text { Website } \\
\text { Fluidity }\end{array}$ & 2 & 1 & 2 & 1 \\
\hline $\begin{array}{l}\text { Network } \\
\text { Visibility }\end{array}$ & 1 & $1 / 2$ & 1 & $1 / 2$ \\
\hline $\begin{array}{l}\text { Volume } \\
\text { of Trade }\end{array}$ & 2 & 1 & 2 & 1 \\
\hline
\end{tabular}


Using Mat LAB7.0, we got matrix A 's maximum latent root and corresponding eigenvector from table 1 :

$$
\begin{gathered}
\lambda_{\max }=4 \\
\mathrm{~W}_{0}=[0.3162,0.6325,0.3162,0.6325]^{\mathrm{T}}
\end{gathered}
$$

The result of the coincident verification to the eigenvector above is as follows:

$$
\begin{gathered}
C I=\frac{\lambda \max -n}{n-1}=\frac{4-4}{4-1}=0 \\
C R=\frac{C I}{R I}=0<0.1
\end{gathered}
$$

CI stands for coincidence index; RI, average random coincidence index and CR, coincidence ratio. In general, when $\mathrm{CR}<0.1$, we can judge that the matrix has satisfactory coincidence. So the eigenvector corresponding with matrix A from table 1 satisfies the coincidence verification. After the further process to the eigenvector, we can get the vector of the weight of every index: $W$ $=[0.1666,0.3334,0.1666,0.3334]^{\mathrm{T}}$.

Identically, we can get the weight of the second class, and figure out all the weights of every index eventually. See the result of every weight in table 2.

Table 2. China $\mathrm{C} 2 \mathrm{C}$ Website Evaluating Indexes and Weight

\begin{tabular}{|c|c|l|c|}
\hline First Class Index & Weight & \multicolumn{1}{|c|}{ Second Class Index } & Weight \\
\hline \multirow{2}{*}{ Network Impact } & \multirow{2}{*}{0.16660} & No. of Inlink Webpages & 0.1111 \\
\cline { 3 - 4 } & & No. of Inlink Websites & 0.0555 \\
\hline \multirow{3}{*}{ Website Fluidity } & \multirow{3}{*}{0.33340} & No. of Visiting & 0.0787 \\
\cline { 3 - 4 } & & No. of Pages Visited & 0.0637 \\
\cline { 3 - 4 } & & Avg. Pages Visited & 0.1273 \\
\cline { 3 - 4 } & & Avg. Load Time & 0.0637 \\
\hline Network Visibility & 0.16660 & Network Visibility & 0.1666 \\
\hline Volume of Market Trade & 0.33340 & Ratio of Volume of Market Trade & 0.3334 \\
\hline
\end{tabular}

\section{Analysis of Application}

\subsection{Data Source and Method}

So far there is no authoritative organization to report the data of every index listed above comprehensively, thus the data source comes from different organizations. In order to keep the time of the data coincident, the time span of the data of every index is from Jan.1st, 2006 to Dec.31st, 2006. 
(1)With the command of "link:" from Google and AltaVista, we got the number of Inlink Webpages of the measured object. On account of the limitation of every search engine's coverage, we chose the data whose numerical value is bigger.

(2)From Alexa,we acquired the number of visiting, number of pages visited, the number of Inlink Websites and average load time. Alexa, which was founded in Apr, 1996, is one of the most famous organizations for analysis of network fluidity and rank of websites. The data comes from "Alexa Toolbar" which is installed on the client. Owing to the fact that some data appeared monthly, the average data of 12 months is taken as the value of indexes.

(3)With the command of "site:" from Baidu,Google,Yahoo,AltaVista and AlltheWeb separately, we acquired the network visibility of measured object. Since network visibility reflects the potential possibility of the research object, we drew weight according to the ratio of usage of these five search engines and took the processed result as the value of network visibility. The way of calculation is the same as that of the first class index above. The ultimate weight of Baidu,Google,Yahoo,AltaVista and AlltheWeb is $0.4834,0.2964,0.1622,0.029,0.029[3]$.

(4)From iResearch survey data we obtained ratio of volume of market trade in 2006 of China C2C websites. iResearch Consulting Group, founded in 2002, is a professional market survey organization, paying attention to the economic fields such as network media, E-commerce, network games and etc.; it also studies and comprehends customers' behaviors deeply and offers market survey research and strategic counseling to network and traditional industry. iResearch Consulting Group studies market and presents reports of investigated data every year.

(5)Due to the unit difference among indexes above, all the data should be processed firstly. The detailed method is making the maximum datum of every index as 100 , then computing other data proportionately, and finally, summing up correspondingly after multiplying the data which are processed.

\subsection{Data Analysis}

Some typical websites of China $\mathrm{C} 2 \mathrm{C}$ are Taobao,eBay,paipai. These websites are used as examples for analysis using the index and weight above.

4.2.1 Final Rank

From the final score, we can see that Taobao website's capability is strongest, and followed by eBay and paipai. See the details in table 3 .

Table 3. Data of every index, final score, and rank of three China $\mathrm{C} 2 \mathrm{C}$ websites

\begin{tabular}{|l|c|c|c|}
\hline \multicolumn{1}{|c|}{ Rank } & $\mathbf{1}$ & $\mathbf{2}$ & $\mathbf{3}$ \\
\hline Name of Website & Taobao & eBay & paipai \\
\hline No. of Inlink Webpages (Unit: million) & 19.2 & 103 & 48.9 \\
\hline No. of Inlink Websites (Unit: thousand) & 59.051 & 9.983 & 1.505 \\
\hline No. of Visiting (Unit: thousand) & 15.755 & 7.091 & 3.325 \\
\hline No. of Pages Visited (Unit: thousand) & 258.027 & 20.318 & 44.414 \\
\hline Avg. Pages Visited & 16.43 & 6.67 & 6.86 \\
\hline Avg. Load Time (Unit: s) & 10.4 & 4.62 & 4.2 \\
\hline Network Visibility & 48074.940 & 19.067 & 44.790 \\
\hline
\end{tabular}


System

\begin{tabular}{|l|c|c|c|}
\hline Ratio of Volume of Market Trade & $65.2 \%$ & $26.1 \%$ & $3.5 \%$ \\
\hline Final Score & 100 & 86.51 & 40.28 \\
\hline
\end{tabular}

4.2.2 Website Impact

From the data of number of Inlink WebPages,we can see eBay has the most Inlink Webpages, followed by paipai,and Taobao has the least.Fig.2(a) is the comparison of three website at this index.

From the data supplied from Alex, we can see that number of Inlink WebPages of Taobao is the most. It is almost six times more than that of eBay, and about twelve times more than paipai. Fig.2(b)describes comparison of three websites.

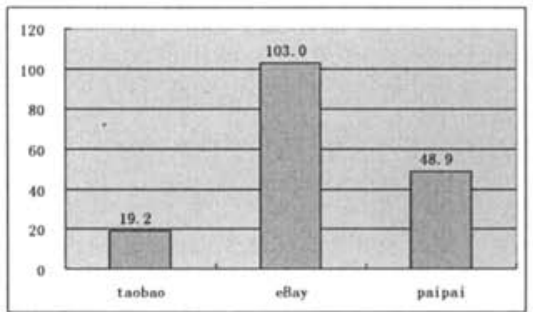

(a) No. of Inlink WebPages (Unit: million)

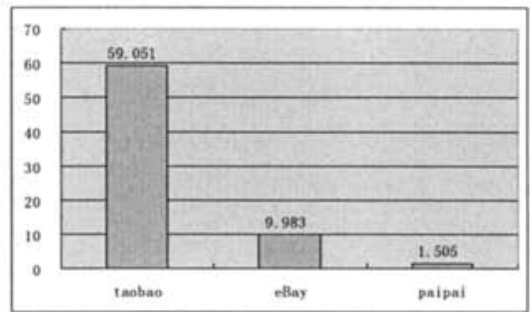

(b) No. of Inlink Websites (Unit: thousand)

Fig.2. Three Websites' Network Impact Comparison

4.2.3 Website Fluidity

(1)Number of People Who Visit and Number of WebPages Visited and Average Webpage per person.

Taobao is always at the first place whether viewed from the index of the number of people who visit or the index of the number of WebPages visited. Fig.3 (a) is can tell more information about these two indexes.

From the index of average WebPages per person, we can see that Taobao is still at the first place. The value of Taobao is more than double of eBay's, and the value between eBay and paipai is closed. See Fig. 3 (b).
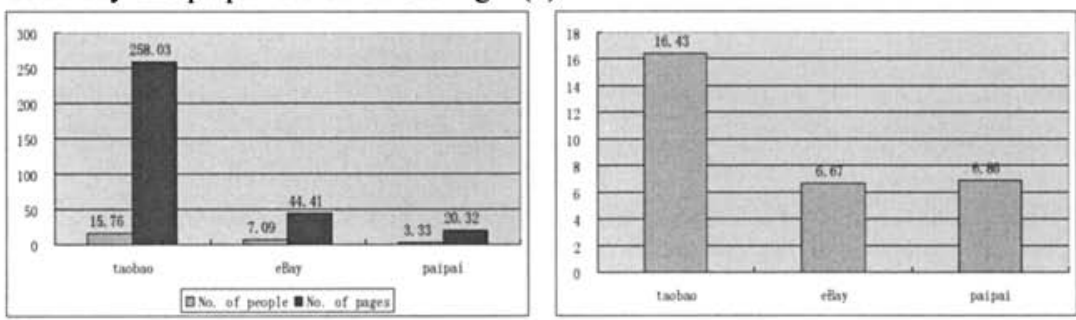

(a) No. of People Who visit and No. of WebPages people visit (b) Avg. WebPages per person

Fig.3. Three Websites' comparison on index of Network Fluidity

From Fig.4 [6], we can see that value of two indexes for three websites is different. Taobao is still the best. The difference between eBay and paipai is small, but eBay is a little better than paipai.
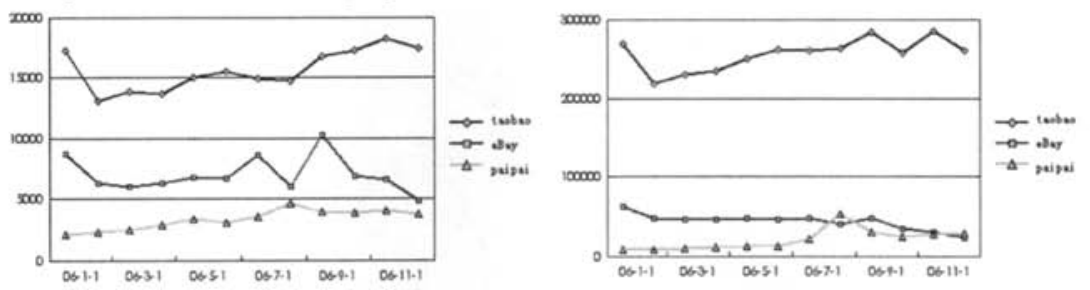
(a)Trend of number of people who visit (b) Trend of number of pages people visit

Fig.4. Comparison of Trend on Index of Network Fluidity

(2)Average Load Time.

From the average load time, Taobao's average load time is $10.4 \mathrm{~s}$, the longest, and is also two times longer than eBay and paipai. The difference between eBay and paipai is small. It shows that Taobao's website fluidity is better than the others. See Table 3.

4.2.4 Network Visibility

From the search engines, we can see that the coverage capacity of Yahoo,AltaVista and AlltheWeb is better than Baidu and Google. From three websites, Taobao's visibility is the best, paipai is the next, and eBay is the worst comparatively. Table 4 can tell the details.

Table 4. No. of Search Result to Taobao,eBay and paipai website using five search engines separately

\begin{tabular}{|c|c|c|c|c|c|c|}
\hline & Baidu & Google & Yahoo & AltaVista & AlltheWeb & $\begin{array}{c}\text { Network } \\
\text { Visibility }\end{array}$ \\
\hline Taobao & 17,300 & 10,800 & 997,000 & 666,000 & 593,000 & 48074.940 \\
\hline eBay & 4 & 2 & 90 & 38 & 29 & 19.067 \\
\hline paipai & 45 & 17 & 82 & 86 & 76 & 44.790 \\
\hline
\end{tabular}

4.2.5 Ratio of Volume of Market Trade

The data reported from iResearch Consulting Group in Mar.2007 shows that the total volume of trade of China C2C websites in 2006 is 23 billion RMB. In China C2C shopping market, the first rank is Taobao website, whose volume of trade is 15 million and which takes up $65.2 \%$ of the whole volume of trade; the second rank is eBay website whose volume of trade declined compared with that of in 2005; the volume of trade of paipai website takes up 3.5\%.After analysis, we can see that the centralization of $\mathrm{C} 2 \mathrm{C}$ market is too high and $80 \%$ of the total volume of market trade is taken up by tabao and eBay, with Taobao taking up more than half[4].

Taobao made a quiet great progress last year and unhinged a long distance from others. There are two causes to explain this phenomenon. First, Taobao kept its élan and played down doorsill of Internet shopping. For example, in May, 2006, Taobao conducted "Taobao business city" which changed the impression of no big brand in business stores on Internet and which made customers who have brand trend more choice. Second, the basic service was absolutely for free, which offered much more opportunity for all members of society to participate. These people are not only the customers of Taobao, but they lead other people around them to be customers of Taobao. I think Taobao will continue the line of being free. See the detail ratio of volume of market trade of three websites in Fig.5. 


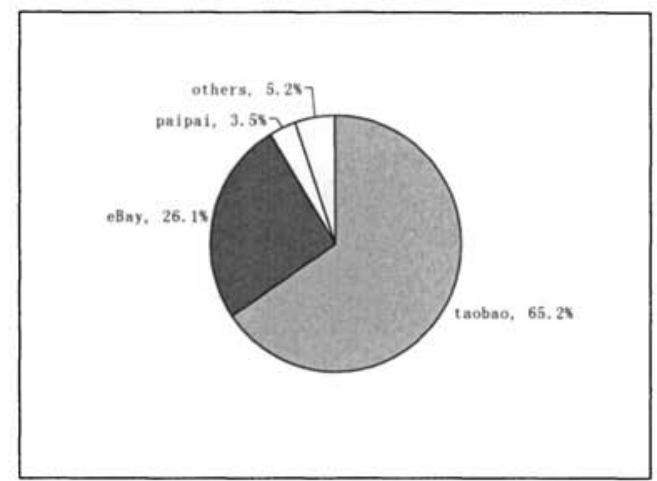

Fig.5. Volume of China C2C Website Market Trade in 2006

\subsection{Result and Suggestion}

(1)From data analysis of every index above we can see that Taobao is almost the first rank. I think there are several causes at work. Taobao was supported by Alibaba, which was a famous B2B website when it was founded, so many running ways are advanced. Although it is a short time since Taobao was founded, they have been able to attract a large volume of customers in China, we should learn more from it.

(2)From the analysis above, we can see the network visibility of Taobao is much better than others. Network visibility is an index to weigh the potential possibility of a website, so the bigger the value of network visibility of a website, the more the number of people who visit this website, the more the number of pages people reach, and the more the volume of market trade of a website. So other websites should learn of this from Taobao, that is, increasing the potential possibility of a website is vital.

(3)Trend of development. The data from Alexa, from Apr.12th, 2006 to Apr.13th,2007 shows that Taobao still keeps its predominance at the first place, and the difference between eBay and paipai is still small. From the time coordinate, the maximum data of every website is in October and January, which is reasonable because October and January are vacation days, then people have more leisure time to go shopping, but less in normal days [1].
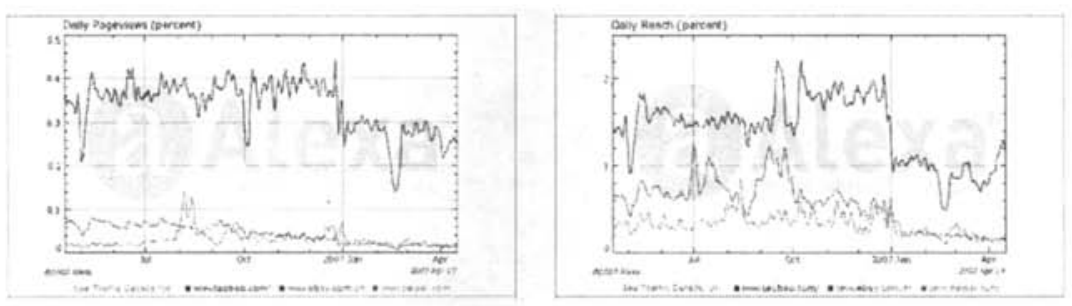

(a) Daily Reach Picture of Three Websites (b) Daily Pageviews Picture of Three Websites Fig.6. Comparison of Three Websites' Daily Reach and Daily Pageviews 


\section{Conclusion}

In this article we take Network Impact, Website Fluidity, Network Visibility and Volume of Trade as the first class index, use AHP method and Mat LAB software to compute the weighing of every index, and design China $\mathrm{C} 2 \mathrm{C}$ website evaluating index system. Acquiring corresponding data from the famous Alexa and iResearch Consulting Group, we analyze the application to three websites (Taobao,eBay and paipai),and give my conclusion and suggestion.

Of course, there is also a big problem facing to China $\mathrm{C} 2 \mathrm{C}$ website that is credit standing. Because credit standing is affected by China law and the rule of law, it cannot be solved in a short time. So future work is to survey and collect data from market carefully and study on it. I hope customers' credit standing behavior can be regulated in future.

\section{Acknowledgement}

This research was supported by the National Natural Science Foundation of China under Grant No. 70673071.

\section{References}

1. Alex Toolbar Search Result.http:/www.alexa.com/data/details/traffic_details?url =www. TaoBao.com\%2F. [2007-04-17].

2. China Internet Network Information Center. http:/www.cnnic.net.cn/index.htm.[200704-13].

3. iResearch China Internet Industry Research Report. http://www.iresearch.com.cn/html/detai 1_free_id_39170.html. [2007-04-13].

4. iResearch China Internet Industry Research Report 2007. http://www.iresearch.com.cn/html/

online_media/detail_free_id_42306.html. .[2007-04-16].

5. iResearch China Online Shopping Research Report 2006. http://www.iresearch.com.cn/html/Online_Shopping/detail_free_id_41269.html.[2007-04-15].

6. iResearch Consulting Group.http://www.iresearch.com.cn/html/Default.html..[2007-0413].

7. W. Liu and D. Yu-feng, Evaluating Performance of E-Government Construction Based on Web Impact,Journal of Information Science, 24(11), 1705-1706(2006).

8. X.H. Ma and B.L. Liu, Application of AHP in the Construction of the Management of Information System, Journal of Science and Technology Management Research,(4), 193194(2006).

9. R.R. Larson, Bibliometrics of the World Wide Web:An Exploratory Analysis of the Intellectual Structure of Cyberspace, http:/www.ischool.berkeley.edu/ ray/ papers.html. [2007-08-13] 
442 Analysis on Research and Application of China C2C Websites Evaluating Index

System

10. T.C. Almind and P. Ingwersen, Informetric Analysis on the World Wide Web: Methodological Approaches to 'Webometrics',Journal of Documentation ,53(4), 404426(1997).

11. L.F. Wang and S.B. Xu, The Theory of AHP ,China Renmin University Press, Beijing(1990).

12. W.J. Wang, Analysis and Comment on Study and Application of EC Website Evaluation, Journal of Information Science, 21(6), 641-642(2003). 